\title{
Clinical Characteristics Analysis on Acute Kidney Injury of Patients in Department of Critical Care Medicine
}

\author{
Xiaoming $\mathrm{Si}^{1}$, Feng $\mathrm{Ke}^{2 \text {, a }}$ \\ ${ }^{1}$ Department of Comprehensive Medicine \\ ${ }^{2}$ Department of Ophthalmology, Renmin Hospital, Hubei University of Medicine, Shiyan, Hubei, \\ China, 442000
}

Address: Chaoyang District Road No. 39, Shiyan City, Hubei Province, P. R. China, 442000

a'Corresponding author: Feng Ke, E-mail: hubeiwenbo@163.com

Keywords: Department of Critical Care Medicine; acute kidney injury; clinical characteristics

\begin{abstract}
To analyze clinical characteristics of acute kidney injury of patients in Department of Critical Care Medicine, the paper selects 100 patients in the intensive care unit (ICU) received by the hospital from January 2016 to December 2017 as the observation group, and 100 common inpatients in the same period are selected as the control group. Clinical characteristics of acute kidney injury of both groups were analyzed comprehensively. Results show that, the incidence rate of acute kidney injury in the observation group was $56.0 \%, 5.0 \%$ higher than that of control group, $(\mathrm{P}<0.05)$. Among the two groups of patients with acute kidney injury, acute kidney injury was mostly induced by multiple organ failure, septicopyemia and shock. So it is concluded, for the patients in ICU, the incidence rate of acute kidney injury is high, which is mostly caused by multiple organ failure, septicopyemia and shock.
\end{abstract}

Acute kidney injury as one of clinical syndromes is very harmful to patients. It may easily result in death. The data show that, acute kidney injury will happen to about $30 \%$ of patients in ICU. This proportion is obviously higher than the incidence rate of acute kidney injury of common inpatients. Acute kidney injury has great influence on patients' treatment and prognosis effect. Thus, 100 patients in the intensive care unit (ICU) received by our hospital from January 2016 to December 2017 were chosen as the observation group, and 100 common inpatients in the same period were selected as the control group to explore incidence rate and characteristics of acute kidney injury as follows:

\section{DATA AND METHOD}

\subsection{General data}

In this research, 100 patients in the intensive care unit (ICU) received by our hospital from January 2016 to December 2017 were chosen as the observation group, and 100 common inpatients in the same period were selected as the control group. Inclusion criteria: age $\geq 18$; complete clinical data; duration of hospitalization $>24 \mathrm{~h}$; patients and (or) their family members knew the research content, and signed the informed consent form. Exclusion criteria (the patients were excluded in case of one of the following conditions): patients with maintenance hemodialysis; patients with renal transplantation; value of serum creatinine during hospitalization $<50 \mathrm{umol} / \mathrm{L}$. In the observation group, there were 59 male patients and 41 female patients, with the age of 43-79 and average value of $60.13 \pm 2.75$. In the control group, there were 57 male patients and 43 female patients, with the age of $45-81$ and average value of $62.38 \pm 2.16$. The comparison of clinical baseline data between both groups had no difference, $\mathrm{P}>0.05$.

\subsection{Method}

The clinical basic data of both groups were sorted out in detail, including name, age, gender, department and disease diagnosis. Then, kidney perfusion factors before/when acute kidney injury happens were gathered, including blood volume and cardiorenal syndrome, peripheral 
hemangiectasis and renal vasoconstriction as well as expansion imbalance, etc. Meanwhile, patients' data about the history of major surgeries were collected, including cardiosurgery, and surgeries in orthopedics department, thoracic surgery department and neurosurgery department, etc[1][2].

\subsection{Diagnostic criteria}

Diagnostic criteria refer to clinical practice of Kidney Disease: Improving Global Outcomes (KDIGO)[3]: (1) $48 \mathrm{~h}$ serum creatinine rise $\geq 0.3 \mathrm{mg} / \mathrm{dL}$ or serum creatinine rise $\geq 1.5$ times of basic value; (2) appear within $7 \mathrm{~d}$ or urine volume $<0.5 \mathrm{ml} \cdot \mathrm{kg}^{-1} \cdot \mathrm{h}^{-1}$ for continuous $6 \mathrm{~h}$.

\subsection{Statistical method}

SPSS 20.0 statistics software was used to analyze clinical data. Measurement data were expressed with ( $x \pm s$ ), and tested with t test. Enumeration data were expressed with (\%), and tested with chi-square test. $\mathrm{P}<0.05$ means the difference has statistical significance.

\section{RESULTS}

In the observation group, there were 56 patients with acute kidney injury (56.0\%), 14 patients with multiple organ failure (25.0\%), 15 patients with septicopyemia (26.8\%), 1 patient with terminal malignant tumor (1.8\%), 4 patients with acute respiratory distress syndrome (7.1\%), 20 patients with shock (35.7\%) and 2 patients treated with tracheal intubation respirator. In the control group, there were 5 patients with acute kidney injury (5.0\%), 2 patients with multiple organ failure (40.0\%), 2 patients with septicopyemia (40.0\%), and 1 patient with shock (20.0\%). The incidence rate of acute kidney injury in the observation group is 5.-\% higher than that in the control group, $\mathrm{P}<0.05$. The patients with acute kidney injury in both groups were mostly caused by multiple organ failure, septicopyemia and shock. The detailed information is shown in Tab.1.

Tab.1 Clinical characteristics analysis of patients with acute kidney injury (\%, n)

\begin{tabular}{|c|c|c|c|c|c|c|c|c|}
\hline Group & $\begin{array}{c}\text { No } \\
\text {. }\end{array}$ & $\begin{array}{c}\text { Acute } \\
\text { kidney } \\
\text { injury }\end{array}$ & $\begin{array}{c}\text { Multiple } \\
\text { organ } \\
\text { failure }\end{array}$ & $\begin{array}{l}\text { septicopye } \\
\text { mia }\end{array}$ & $\begin{array}{l}\text { terminal } \\
\text { malignan } \\
\text { t tumor }\end{array}$ & $\begin{array}{c}\text { Acute } \\
\text { respirato } \\
\text { ry } \\
\text { distress } \\
\text { syndrom } \\
\text { e }\end{array}$ & Shock & $\begin{array}{c}\text { Treatme } \\
\text { nt with } \\
\text { tracheal } \\
\text { intubatio } \\
n \\
\text { respirato } \\
\text { r }\end{array}$ \\
\hline $\begin{array}{l}\text { Observa } \\
\text { tion } \\
\text { group }\end{array}$ & $\begin{array}{c}10 \\
0\end{array}$ & $\begin{array}{c}56 \\
(56.0 \% \\
)\end{array}$ & $\begin{array}{c}14 \\
(25.0 \%)\end{array}$ & $15(26.8 \%)$ & $1(1.8 \%)$ & $4(7.1 \%)$ & $\begin{array}{c}20 \\
(35.7 \% \\
)\end{array}$ & $2(3.6 \%)$ \\
\hline $\begin{array}{c}\text { Control } \\
\text { group }\end{array}$ & $\begin{array}{c}10 \\
0\end{array}$ & $\begin{array}{c}5 \\
(5.0 \%)\end{array}$ & $\begin{array}{c}2 \\
(40.0 \%)\end{array}$ & $2(40.0 \%)$ & $0(0.0 \%)$ & $0(0.0 \%)$ & $\begin{array}{c}1 \\
(20.0 \% \\
)\end{array}$ & $0(0.0 \%)$ \\
\hline $\begin{array}{l}\text { Value of } \\
X^{2}\end{array}$ & - & 61.3516 & 9.7826 & 10.8647 & 1.0050 & 4.0816 & 19.2072 & 2.0202 \\
\hline $\begin{array}{c}\text { Value of } \\
\mathrm{P}\end{array}$ & - & 0.0000 & 0.0018 & 0.0010 & 0.3161 & 0.0434 & 0.0000 & 0.1552 \\
\hline
\end{tabular}

\section{DISCUSSION}

Acute kidney injury is a clinical syndrome. The renal function of patients with acute kidney injury suddenly declines within $1-7 \mathrm{~d}$ and the time of duration $>24 \mathrm{~h}$. Clinically, patients' serum creatinine rises $\geq 0.5 \mathrm{mg} / \mathrm{dL} 1$, and such symptoms frequently appear as azotemia, in-vivo water-electrolyte and acid-base equilibrium or multisystem symptom. Besides, oliguria (urine volume $<400 \mathrm{ml} / 24 \mathrm{~h}$ or $17 \mathrm{ml} / \mathrm{h}$ ) or anuria (urine volume $<100 \mathrm{ml} / 24 \mathrm{~h}$ is often seen. Usually, continuous development $f$ the disease will result in multi-organ and system injury, and even death. 
Thus, it is required to diagnose as soon as possible, and conduct symptomatic and supportive treatment and kidney replacement therapy according to patients' conditions so as to avoid the threat of life safety [4].

Based on the above analysis of acute kidney injury, it is known that it is required to comprehensively understand morbidity and induction factors of acute kidney injury so as to reduce incidence rate and death rate of this disease and provide the reference for clinical treatment. Data show that, the incidence rate of acute kidney injury of patients in ICU is about $50 \%$, so 200 patients were included in this research. According to their hospitalization situations, they were classified into the control group (common inpatients) and the observation groups (patients in ICU). Contrastive analysis was conducted after detailed sorting out of clinical data. The results are as follows: the incidence rate of acute kidney injury of patients in ICU was 56.0\%, and the difference existed, compared with the control group (5.0\%); acute kidney injury was mostly caused by multiple organ failure, septicopyemia and shock.

Usually, when multiple organ failure happens, inflammatory mediator damaging blood vessel endothelium will release in quantity, and renal blood flow will decrease, thus leading to acute kidney injury. There have report found that independent risk factors for inpatients' death usually include advanced age, hospitalization in ICU, acute kidney injury diagnosis staging and renal replacement therapy as well as organ failure, etc[5]. Hence, when the patients with severe acute kidney injury are combined with multi-organ incompetence, it is required to actively treat as early as possible according to the disease condition, strictly control the protopathy, overall assess the order of severity, give scientific and all-round treatment and pay attention to prevention of other organ injury.

The patients with septicopyemia often have systemic inflammatory response, and it is also one of clinical syndromes. It has high probability of causing acute kidney injury. The patients with acute kidney injury caused by septicopyemia mostly have hypourocrinia and azotemia, and disturbance of water and electrolyte or metabolic acidosis give rise to multisystem complications. Clinically, multiple organ failure and acute kidney injury may easily occur in the disease development of septicopyemia. When patients' multiple symptoms occur simultaneously, the time of hospitalization will lengthen, and the death rate will increase ${ }^{[5]}$. Thus, during protopathy treatment for the patients with combined acute kidney injury, it is required to pay high attention to infection control and prevention of multiple organ failure so as to avoid death within a short time due to combination of multiple symptoms and enhance kidney protection. Such therapeutic measure is very important for infectious shock treatment. Meanwhile, if the decrease of renal blood flow leads to insufficient kidney perfusion, it is required to clear the metabolites and stably keep the in-vivo environment and give scientific renal replacement therapy according to patients' conditions of disease [6][7].

About $0.1 \%$ of patients in ICU induce acute kidney injury due to infectious shock. In such case, the death rate of patients is $30 \%-40 \%$. So, it is required to effective blood circulation in the stick period of patients with acute kidney injury caused by infectious shock, make sure in-vivo blood can be redistributed again, and make sure hear and brain can get sufficient blood supply. Meanwhile, it is also required to attach great importance to disease aggravation caused by insufficient perfusion of other organs, such as dysfunction of gastrointestinal tract, liver and kidney[8][9][10]. After infectious shock, the process of patients' blood flow redistribution will seriously injure kidney, so all-round support and protection of kidney is required. It is also required to continuously enhance disease treatment effect. Therefore, the occurrence of acute kidney injury should be identified as early as possible so as to provide scientific and effective treatment for patients, and improve their prognosis significantly. The control and improvement in the early stage of kidney hypoperfusion and in the recovery period should be highly concerned to avoid irretrievable injury to patients' kidney cell function caused by shock.

In conclusion, acute kidney injury may easily occur to the patients in Department of Critical Care Medicine. Symptomatic treatment is required clinically in accordance with patients' detailed conditions. Prevention and treatment of organ failure, septicopyemia and shock should be paid attention to. 


\section{REFERENCES}

[1] Arora RC, Tangri N, All that glitters may not be gold: Changes in serum creatinine may not be the criterion standard foracute kidney injury, J Thorac Cardiovasc Surg. 2018 Feb 8.

[2] Gist KM, Cooper DS, Acute Kidney Injury Biomarkers Predict an Increase in Serum Milrinone Concentration Earlier Than Serum Creatinine-Defined Acute Kidney Injury in Infants After Cardiac Surgery.Ther Drug Monit. 2018 Apr;40(2):186-194.

[3] Patel UD, Garg AX, Krumholz HM, Preoperative serum brain natriuretic peptide and risk of acute kidney injury after cardiac surgery. Circulation. 2012 Mar 20;125(11):1347-55.

[4] Gist KM, Cooper DS, Wrona J, Faubel S, Altmann C, Acute Kidney Injury Biomarkers Predict an Increase in Serum Milrinone Concentration Earlier Than Serum Creatinine-Defined Acute Kidney Injury in Infants After Cardiac Surgery. Ther Drug Monit. 2018 Apr;40(2):186-194.

[5] FANG Y, DING X, ZHONG Y et al. Acute kidney injury in a Chinese hospitalized population [J]. Blood Purif, 2010, 30(2): 120-126.

[6] Li N, Zhao WG, Zhang WF. Acute kidney injury in patients with severe traumatic brain injury: implementation of the acute kidney injury network stage system. Neurocrit Care. 2011 Jun;14(3):377-81.

[7] Ignacak E, Wyrwicz-Zielińska G, Krzysztonek-Weber I, Risk factors of death occurrence in patients with acute kidney injury in the course of severecardio-vascular complications]. Przegl Lek. 2016;73(2):78-82. Polish.

[8] Chen $\mathrm{W}, \mathrm{Hu} \mathrm{Y}$, Zhang $\mathrm{X}, \mathrm{Wu}$ L,Causal risk factor discovery for severe acute kidney injury using electronic health records. BMC Med Inform Decis Mak. 2018 Mar 22;18(Suppl 1):13.

[9] Kamar C, Ali A, Altun D, Orhun G, Evaluation of risk factors and development of acute kidney injury in aneurysmal subarachnoid hemorrhage, head injury, and severe sepsis/septic shock patients during ICU treatment. Ulus Travma Acil Cerrahi Derg. 2017 Jan;23(1):39-45.

[10] A. de Mendonça, Acute renal failure in the ICU: risk factors and outcome evaluated by the SOFA score, Intensive Care Medicine July 2000, Volume 26, Issue 7, pp 915-921. 